\title{
Effect of stearin and paraffin adulteration of beeswax on brood survival
}

\author{
Magdalena ChęĆ ${ }^{1}$, Krzysztof Olszewski ${ }^{2}$, Piotr DziechCiarz ${ }^{2}$, Patrycja SkowroneK ${ }^{2}$, \\ Marek Pietrow ${ }^{3}$, Grzegorz BorsuK ${ }^{2}$, Mirosława BednARCZYK ${ }^{1}$, Grzegorz JAsinA ${ }^{4}$, \\ Józef JASINA $^{4}$, Mariusz GAGOŚ ${ }^{1}$ (D) \\ ${ }^{1}$ Department of Cell Biology, Institute of Biological Sciences, Maria Curie-Skłodowska University, Akademicka 19, 20 - \\ 033, Lublin, Poland \\ ${ }^{2}$ Department of Apidology, Institute of Biological Basis of Animal Production, University of Life Sciences in Lublin, \\ Akademicka 15, 20-950, Lublin, Poland \\ ${ }^{3}$ Department of Material Physics, Institute of Physics, Maria Curie-Skłodowska University, Akademicka 7, 20-031, \\ Lublin, Poland \\ ${ }^{4}$ Beekeeping Farm "Miodek", Lublin, Poland
}

Received 24 April 2020 - Revised 6 November 2020 - Accepted 9 December 2020

\begin{abstract}
The study examined the effect of stearin and paraffin adulteration of the wax foundation on brood survival. In combs formed on a stearin-adulterated wax foundation $(10,30$, and $50 \%$ stearin, which means: $3.9,11.7$, and $19.5 \%$ of stearic acid, respectively), the survival of brood decreased statistically significantly ( $p \leq 0.001)$ compared to the survival rates noted on a pure beeswax foundation. The brood appearance resembled the socalled scattered brood although the queens oviposited normally. The scattered brood was caused by the death of young larvae, most probably due to changes in the properties of royal jelly. Larvae transferred into stearinadulterated wax cups died as well. The adulteration of the wax foundation with paraffin $(10,30$, and $50 \%)$ did not reduce the survival of the brood but lowered the mechanical strength of the combs. Adulteration of wax with even a small amount of stearin/stearic acid makes it useless for apiculture.
\end{abstract}

\section{Apis mellifera / wax adulteration / wax foundation / stearin / paraffin}

\section{INTRODUCTION}

As early as in the 1950s, Tarranow (1959) reported a close relationship between the quality of wax used for construction of wax foundations and the abundance of reared brood, and thus the strength of colonies. However, this problem was marginalized. Currently, Taranow's observations are becoming extremely relevant, especially in light of the 2018 European Commission Health

Corresponding author: M. Chęć,

magdalenachec16@tlen.pl;

K. Olszewski, krzysztof.olszewski@up.lublin.pl;

M. Gagoś, mariusz.gagos@ poczta.umcs.lublin.pl

Manuscript editor: Peter Rosenkranz and Food Safety report, which claims that adulteration of wax with stearin, paraffin, and palm oil exerts a negative effect on bee colonies, showing that the presence of $15-35 \%$ of stearic acid in the wax foundation in relation to pure wax leads to the death of up to $71 \%$ of larvae reared in combs built on such a wax foundation (EU Food Fraud Network 2018).

At present, the problem of wax adulteration has not been sufficiently studied, and preliminary data on the effect of stearin adulteration on the biology of bee colonies have been provided in few studies, only one of which is a peer-reviewed scientific paper, while others are reports (Alkassab et al. 2020; Aupinel 2018; EU Food Fraud Network 
2018; European Food Safety Authority 2020; Reybroeck 2017; Reybroeck 2018). A drawback of these reports is the lack of a description of statistical analysis methods. In our opinion, the significant impact of stearin adulteration of the wax foundation on brood survival gives grounds to consider it as a yet disregarded factor that may contribute to colony collapse disorder (CCD) through the increasing negative impact of such factors as plant protection products on colonies (Calatayud-Vernich et al. 2017; Johnson et al. 2009; Medici et al. 2015; vanEngelsdorp et al. 2017), bee diseases caused by various pathogens (Chen and Evans 2007; Medici et al. 2015; vanEngelsdorp et al. 2017), and inappropriate methods used in apiary management (Sauer et al. 2004). However, only few studies have been carried out to assess the effect of paraffin (Castro et al. 2010; Semkiw and Skubida 2013). No negative influence of the paraffin content in the wax foundation on brood survival has been found.

The problem of beeswax adulteration is important, as the wax is the second most important bee product after honey used not only in beekeeping but also in many industries (paint, arms, metallurgical, pharmaceutical, or cosmetic industries) (Tulloch 1973; Wilmart et al. 2016). The importance of the problem is emphasized by the increasing shortage of wax on global markets, which substantially affects its price. The economic conditions, i.e., the deficit and high price of this raw material, contribute to the sharp decline in the beeswax quality. The deterioration of the quality is associated with addition of much cheaper substances to wax, e.g., non-native hydrocarbons (paraffin), stearin, tallow, or vegetable fats (Bogdanov 2016). Beeswax adulteration has become widespread, as there are no procedures for routine quality control of this raw material sold on the market. Investigations conducted by Svečnjak et al. (2015) or Bogdanov (2016) provide alarming data in this field. The awareness of the problem is increasing, hence the need for beeswax control (Daniele et al. 2018; Eshete and Eshetie 2018; European Food Safety Authority 2007).

The aim of the study was to assess the effect of stearin and paraffin adulteration of wax foundations on the survival of brood reared in combs built on the foundations. Particular emphasis was placed on the cause of emergence of the so-called scattered brood.

\section{MATERIALS AND METHODS}

The investigations were conducted in two beekeeping seasons. In 2018, preliminary research was carried out to assess the effect of beeswax adulteration on the construction of wax foundations and appearance of brood reared therein. Two experiments were conducted in 2019. One of them assessed the development of the worker brood in combs built on an adulterated wax foundation, and the other experiment evaluated the efficiency of rearing bee queens in cells built on cups made of adulterated wax.

The preliminary analyses were carried out on the professional "Miodek" Apiary Farm in Lublin (Poland). The other examinations were performed in the apiary of the Department of Apiculture of the Institute of Biological Basis of Animal Production, University of Life Sciences in Lublin.

The same pool of pure beeswax obtained from the "Miodek" Farm was used for construction of wax foundations in all analyses. The wax was derived from uncapping wax, and no external sources of wax had been used in the apiary for over 50 years. Some beeswax from this pool was adulterated with stearin or paraffin. Next, one wax foundation was made of pure wax and other foundations were constructed from stearin- or paraffinadulterated wax in proportions of 10, 30, and 50\% and denoted as ST10\%, ST30\%, ST50\%, PA10\%, $\mathrm{PA} 30 \%$, and PA50\%. A pure wax foundation was the Control. All wax foundation types were made with the use of roller in the "Miodek" apiary. In total, seven types of wax were evaluated in the experiment.

Stearin (Radiacid 444, Standard sp. z o.o.) and paraffin (Kunlun 56-58, Standard sp. z o.o.) were used in the experiments. Stearin is a solid mixture of stearic and palmitic acids. Its melting temperature depends on the ratio of components. In our case it was $67^{\circ} \mathrm{C}$. The gas chromatography-mass spectrometry (GC-MS) method was used to check the composition of these commercial products. The stearin was composed of $61 \%$ of palmitic acid and $39 \%$ of stearic acid. This accounts for 
$3.8,11.4$, and $19.0 \%$ of stearic acid in the adulterated wax foundation.

Paraffin is a product derived from petroleum as a mixture of long saturated hydrocarbons (alkanes) with tenths (usually from $n=20$ up to 40) of carbon atoms forming molecule's chains. Typically, the ratios of given chain lengths obey a Gaussian distribution function with a maximum at about 30 carbon atoms in a molecule. Since the melting temperature of these hydrocarbons is above the room temperature, the paraffin forms a wax with a melting temperature at $59{ }^{\circ} \mathrm{C}$ in our case. The GC-MS spectroscopy shows that the used paraffin was composed of saturated hydrocarbons (alkanes) with a maximum concentration (14\%) for hentriacontane (31 carbon atoms in a chain). The concentrations of other alkanes form a Gaussian shape function of $n$ given by the estimating formula $A * e^{-B *(n-C)}$, where $A=14.4$, $B=0.07$, and $C=31$. The composition of paraffin and beeswax in terms of the content of longchain alkanes is presented in Table I. In contrast to the composition of paraffin, there are virtually no

Table I. Concentration of hydrocarbons in pure beeswax and laboratory paraffin used in the experiments

\begin{tabular}{|c|c|c|}
\hline $\mathrm{C} n$ & Beeswax (\%) & Paraffin (\%) \\
\hline $\mathrm{C} 24$ & 0.00 & 0.28 \\
\hline $\mathrm{C} 25$ & 0.37 & 0.70 \\
\hline $\mathrm{C} 26$ & 0.00 & 1.33 \\
\hline $\mathrm{C} 27$ & 2.33 & 2.77 \\
\hline $\mathrm{C} 28$ & 1.02 & 7.14 \\
\hline $\mathrm{C} 29$ & 7.01 & 13.74 \\
\hline $\mathrm{C} 30$ & 0.94 & 13.19 \\
\hline $\mathrm{C} 31$ & 32.21 & 14.37 \\
\hline $\mathrm{C} 32$ & 1.05 & 12.21 \\
\hline $\mathrm{C} 33$ & 15.03 & 10.83 \\
\hline C34 & 0.72 & 6.88 \\
\hline $\mathrm{C} 35$ & 10.61 & 4.96 \\
\hline $\mathrm{C} 36$ & 0.49 & 3.15 \\
\hline C37 & 0.00 & 1.79 \\
\hline C38 & 0.00 & 1.36 \\
\hline C39 & 0.00 & 4.01 \\
\hline $\mathrm{C} 40$ & 0.00 & 0.74 \\
\hline C41 & 0.00 & 0.54 \\
\hline
\end{tabular}

hydrocarbons with an even number of carbon atoms in natural waxes. The palmitic acid concentration in the reference beeswax used for the analyses was $4.2 \%$. Furthermore, the following compounds are present in this wax: lignoceric acid (3.3\%), cerotic acid methyl ester $(2.5 \%)$, palmitic acid decyl ester $(16.9 \%)$, and palmitic acid tetradecyl ester $(1.4 \%)$.

The composition of wax, stearin, and paraffin was examined by spectroscopic studies using a Vertex 70 spectrometer (Fourier Transform Infrared Spectrometer, Bruker Optik GmnH, Germany). In the ATR-FTIR spectroscopic measurements, a $\mathrm{ZnSe}$ (zinc selenide) monocrystal was used to provide 20 -fold total internal reflection of the absorbed beam. The results were compared with pure beeswax obtained from combs formed without the use of a wax foundation following the methods proposed by Cuní et al. (2012) and Svečnjak et al. (2015). Table II shows a summary of characteristic bands with their corresponding wave numbers to which specific vibrations are assigned (Table II).

\subsection{Season 2018}

\subsubsection{Preliminary experiment}

In the apiary, six colonies with similar strength and structure occupying five combs (frame $360 \mathrm{~mm} \times 260 \mathrm{~mm}$ ) were selected. Colonies were headed by naturally mated Carniolan sister queens. Three stearin- and three paraffin-adulterated wax foundations $(10,30$, and $50 \%$ ) were constructed. The wax foundation was inserted into frames with vertical wires. The frames with the wax foundations were placed in the colonies. In each colony, there was only one experimental frame located in the middle of the nests. In the absence of nectar flow, the colonies were fed a 1:1 mixture of water and honey. After building the combs, queen oviposition, and filling the combs with food administered to the colonies before winter, the combs were photographed to document the appearance of the brood (Figure 1) and the food storage combs (Figure 2). 
Table II. Characteristic bands in the spectra of pure beeswax, stearin, and paraffin and the type of vibrations $(\nu$, stretching vibrations; $\delta$, deformation vibrations; $s$, symmetric vibrations; as , asymmetric vibrations)

\begin{tabular}{|c|c|c|c|}
\hline \multicolumn{3}{|l|}{ Wavenumber $\left(\mathrm{cm}^{-1}\right)$} & \multirow[t]{2}{*}{ Type of vibration } \\
\hline Beeswax & Stearin & Paraffin & \\
\hline 2955 & 2954 & 2955 & $v_{\mathrm{as}}\left(\mathrm{CH}_{3}\right)$ \\
\hline 2915 & 2914 & 2915 & $v_{\text {as }}\left(\mathrm{CH}_{2}\right)$ \\
\hline- & 2638 & - & $v(\mathrm{O}-\mathrm{H})$ \\
\hline 2848 & 2847 & 2848 & $v_{\mathrm{s}}\left(\mathrm{CH}_{2}\right)$ \\
\hline 1736,1711 & 1696 & - & $v(\mathrm{C}=\mathrm{O})$ \\
\hline- & 1540 & - & $v_{\text {as }}(\mathrm{COO}-)$ \\
\hline 1472,1463 & 1471,1463 & 1473,1463 & $\delta(\mathrm{C}-\mathrm{H})$ \\
\hline 1414 & 1410 & - & $v_{\mathrm{s}}(\mathrm{COO}-)$ \\
\hline 1378,1345 & 1375,1347 & 1378,1345 & $\delta\left(\mathrm{CH}_{2}\right)$ \\
\hline $\begin{array}{l}1329,1309,12881266,1243 \\
1220,1196\end{array}$ & $\begin{array}{l}1330,1310,1295,1277,1270,1258 \\
1248,1226,1205,1121\end{array}$ & - & $v(\mathrm{C}-\mathrm{O})$ \\
\hline- & 1239,1099 & - & $v_{\mathrm{s}}\left(\mathrm{PO}_{2}^{-}\right)$ \\
\hline \multirow[t]{3}{*}{1171} & 1187 & - & $v(\mathrm{C}-\mathrm{O}-\mathrm{C})$ \\
\hline & 933 & - & $\delta(\mathrm{C}-\mathrm{H})$ \\
\hline & - & 889 & $v(\mathrm{C}-\mathrm{O})$ \\
\hline
\end{tabular}

\section{EXPERIMENT 2018}

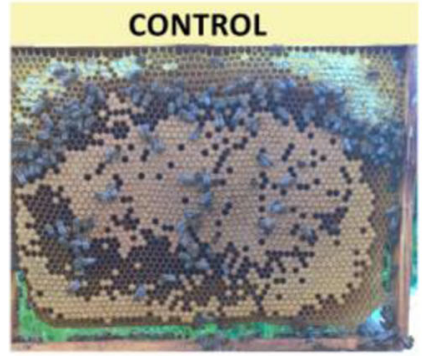

STEARIN $10 \%$

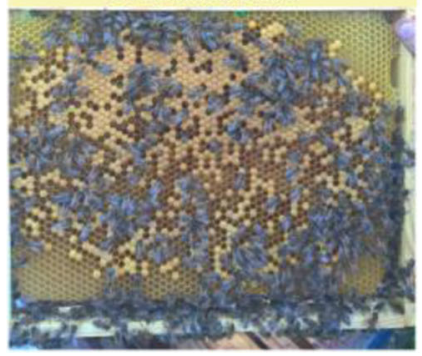

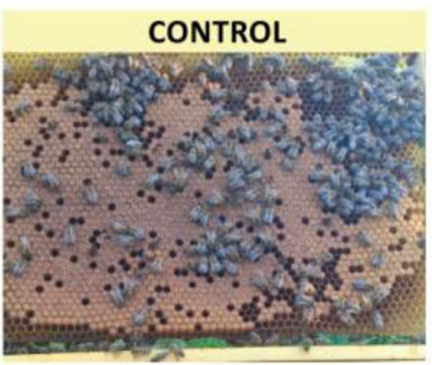

STEARIN 30\%

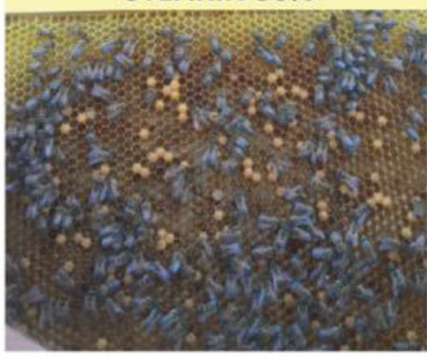

CONTROL

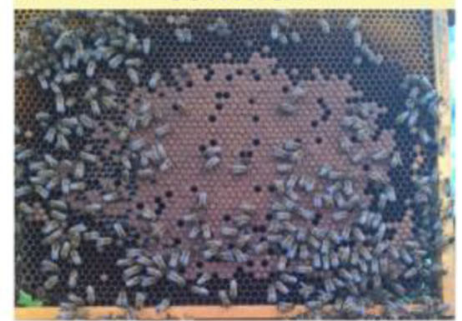

STEARIN 50\%

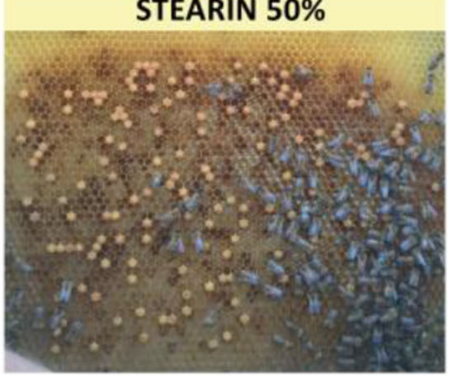

Figure 1. Experiment 2018, image of scattered brood reared in combs built on a wax foundation adulterated with 10, 30 , and $50 \%$ of stearin. 


\section{EXPERIMENT 2018}
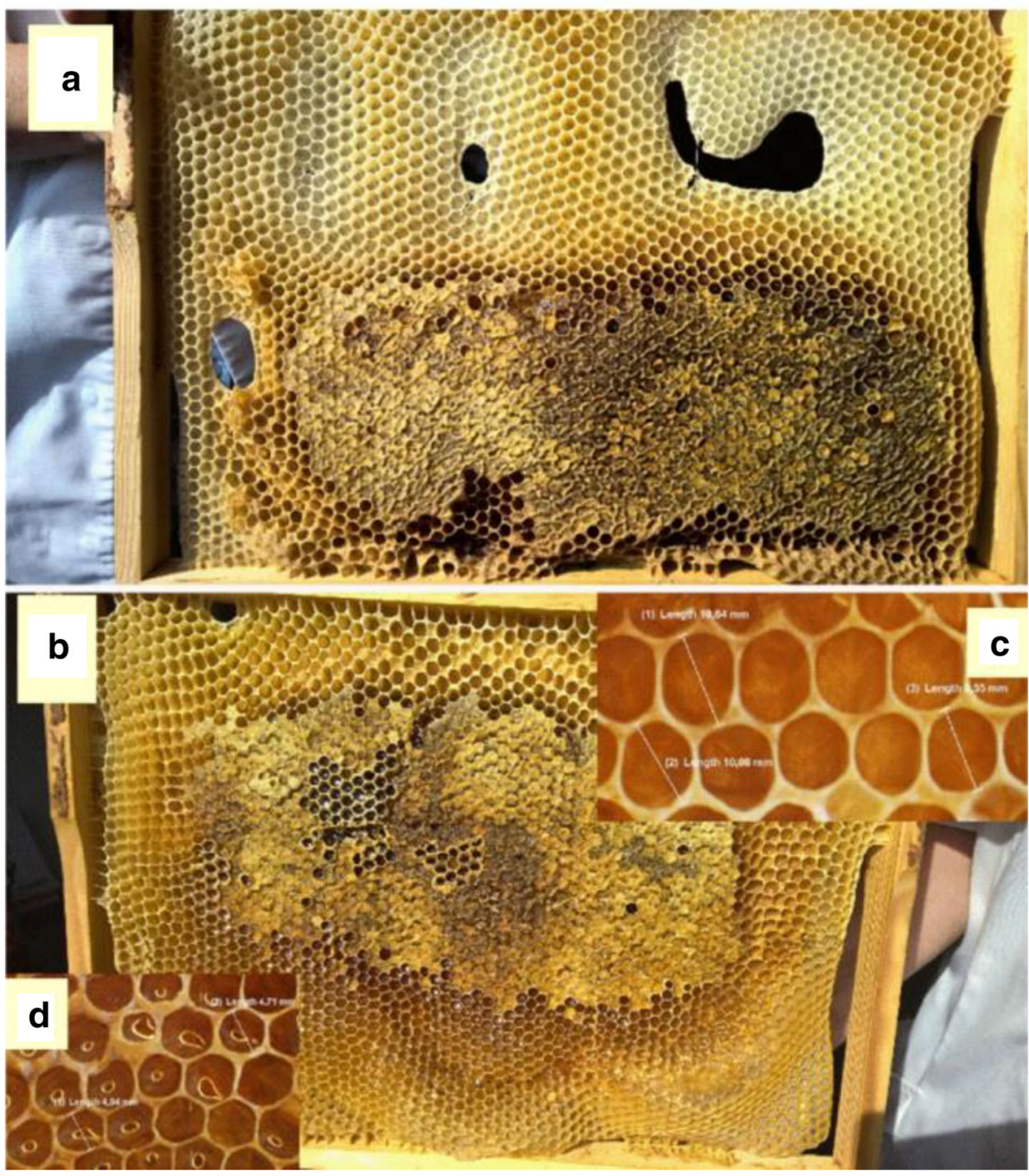

Figure 2. Experiment 2018, atypical changes in combs built on a paraffin-adulterated wax foundation and filled with food; a 30\% paraffin, b 50\% paraffin. a - comb with the upper part sliding significantly under the weight of food. The empty space was built up by bees. $\mathbf{b}$ - comb partly filled with food and considerable cell deformation in the upper and lower parts caused by the slide. $\mathbf{c}, \mathbf{d}$-deformation of cells in patch $\mathbf{b}: \mathbf{c}$-vertical stretching of the cells to an average height of $10 \mathrm{~mm}$, $\mathbf{d}$ pressed cells in the lower part of the comb to an average height of $4 \mathrm{~mm}$ under the pressure of the upper part.

\subsection{Season 2019}

\subsubsection{Worker brood survival}

The results of preliminary tests prompted us to continue the research. To avoid potential deformation of the combs and to obtain combs with similarly aged brood, the experiment was conducted in nucleus colonies with a small frame $(210 \mathrm{~mm} \times 170 \mathrm{~mm})$. Each colony occupied three brood chambers with six combs in each chamber.

For building the combs, three frames with each type of adulterated wax foundations (ST10\%, ST $30 \%$, ST $50 \%$, PA $10 \%$, PA30\%, PA50\%) were placed in a separate strong colony. Nine frames with the pure wax foundation were placed in each 
of the two colonies. The queens were separated by a queen excluder to these frames. In the absence of nectar flow, the colonies were fed water with honey in a 1:1 ratio. After building, the combs were removed from the colonies.

Next, 18 nucleus colonies with similar strength and structure were selected. Colonies were headed by naturally mated Buckfast sister queens. One to three nucleus colonies were transferred onto the experimental combs formed on each of the six types of the adulterated wax foundations. For fast oviposition, the comb was placed between the brood combs in the central brood chamber of each colony. After a day, a control comb built on a pure wax foundation was placed in each colony next to the experimental comb. The colonies were not fed, as they still had moderate nectar flow. After 2 days, the combs in each colony were filled entirely with brood/eggs.

Next, the experimental combs in each colony were photographed on day 10 to document the appearance of the brood. Based on the photographs, capped brood cells were counted in each comb (Figures 5 and 6). A representative 2- $\mathrm{dm}^{2}$ area (approximately 800 cells) was selected on both sides of each comb (front and back). On each of these surfaces, the capped brood cells were counted. The numbers of capped brood cells on both sides of each comb were totaled, which gave 3 measurements for each level of stearin or paraffin adulteration and 3 measurements of the pure wax control combs for each adulteration level. The cells were counted using ImageJ analysis software version 1.51j8 for Windows (2018), Open Software, using the Multipoint tool. Anomalies in brood rearing were documented as well (Figure 7).

\subsubsection{Queen larva survival}

Queen cell cups were made from each of the seven types of wax (ST10\%, ST30\%, ST50\%, PA $10 \%$, PA30\%, PA50\%, and Control). The cups were attached to bars in a queen-rearing frame in the following order: the first bar-Control, Control, Control, ST50\%, ST50\%, ST50\%, Control, Control, Control, ST30\%, ST30\%, ST30\%, Control, Control, Control, ST10\%, ST10\%, ST10\%, Control, Control, Control and the second
bar-Control, Control, Control, PA50\%, PA50\%, PA50\%, Control, Control, Control, PA30\%, PA30\%, PA30\%, Control, Control, Control, PA10\%, PA10\%, PA10\%, Control, Control, Control (Figure 8). Two such frames were prepared. One-day-old larvae were placed onto royal jelly in the cups. Each frame contained 24 pure wax cups (Control), 9 stearin-adulterated wax cups (3 ST10\% + 3 ST30\% + ST50\%), and 9 paraffin-adulterated wax cups (3 PA10\% + 3 PA30\% + 3 PA50\%). The frames were placed in two strong colonies reared without a queen (one frame in each colony). Six days after transferring the larvae, the queen-rearing frames were removed from the colonies and the queen cells were photographed. Based on the photographs, the percentage of built queen cells was calculated relative to the number of cups with larvae. Calculations for stearin- and paraffin-adulterated wax were combined for all levels of addition of the substances $($ stearin $=\mathrm{ST} 10 \%+\mathrm{ST} 30 \%+\mathrm{ST} 50 \%$ and paraffin $=\mathrm{PA} 10 \%+\mathrm{PA} 30 \%+\mathrm{PA} 50 \%)$.

\subsection{Statistical analysis}

The results were analyzed statistically using Statistica software formulas, version 13.3 (2017) for Windows, StatSoft Inc., USA.

The distribution of the data was analyzed with the Kolmogorov-Smirnoff test. Next, the data were analyzed with one-way ANOVA. The significance of the differences between the combs formed on the wax foundation with each level of adulteration and the control for each adulteration level was determined with Tukey's post hoc test for independent samples.

Statistical analysis of the number of queen cell cups formed on each of the types of wax was carried out using the chi $^{2}$ test for the observed numbers relative to the expected ones.

\section{RESULTS}

\subsection{Season 2018}

\subsubsection{Preliminary experiment}

Survival of brood reared in combs built on the stearin-adulterated wax foundations (STCombs) 
was significantly lower than in combs on the pure wax foundations (WCombs) (Figure 1) or paraffin-adulterated wax foundations (PACombs). Scattered brood was observed in the STCombs (combs built on the stearinadulterated wax foundations), and the number of capped brood cells decreased with the increasing stearin content (Figure 1). The brood reared in the PACombs had normal appearance, although it was concentrated on a small area due to the comb deformation. However, the PACombs were found to slide vertically and were deformed by the weight of the stored food (Figure 2). This suggests that the addition of paraffin to the wax foundation does not affect the brood but significantly reduces the mechanical strength of the combs and thus causes substantial losses in honey production.

\subsection{Season 2019}

\subsubsection{Worker brood survival}

There was no significant effect of the condition of a colony on the number of capped brood cells in the WCombs, colonies where stearin-adulterated combs were placed $(\mathrm{df}=2$, $F=0.36, p=0.71$ ), or colonies with paraffinadulterated combs $(\mathrm{df}=2, F=0.28, p=0.77)$. The results of the survival of brood in the adulterated combs were consistent with those obtained in the preliminary experiment. The paraffin content in the wax foundation $(\mathrm{df}=$ 2, $F=1.23, p=0.36$ ) had no effect on brood survival, whereas a significant effect of stearin was noted ( $\mathrm{df}=2, F=463.30, p=0.000)$. A characteristic feature of the stearin-adulterated wax foundation was the presence of scattered brood in the combs (Figures 3 and 7), which was not observed in the case of the paraffinadulterated foundations (Figure 4). Consequently, compared to the WCombs, the stearin adulteration of the wax foundation significantly reduced the brood survival in the combs (ST10\% $p \leq 0.001$, ST30\% $p \leq 0.001$, ST50\% $p \leq 0.001$ ) (Figure 5). In turn, the paraffin adulteration did not affect brood survival (Figure 6). With the increase in the stearin content in the wax foundation, the survival of brood in the STCombs decreased. The rates of brood survival in the combs built on wax foundations adulterated with $30 \%$ and $50 \%$ of stearin were at the same level. However, they were significantly lower than in the combs built on the wax foundation adulterated with $10 \%$ of stearin $(p \leq 0.001)$. These results demonstrated that the $10 \%$ stearin addition to the wax foundation induced a $67 \%$ decline in the brood survival, compared to the control, which indicated a survival rate of $33 \%$ (Figure 3). However, at the 30 and 50\% stearin addition to the wax foundation, the brood survival in the STCombs was $13 \%$ and $8 \%$, respectively, relative to the control.

It was observed that the queens laid eggs normally into each cell in all types of combs (WCombs, STCombs, and PACombs). Therefore, to determine the causes of the emergence of scattered brood only in the STCombs, the combs were photographed on day 6 after transfer into the colonies (Figure 7). Normally developing larvae were found only in a few cells. Some larvae were found directly on the bottom of some cells rather than on the drop of royal jelly, which undoubtedly contributed to their death. This was confirmed by the fact that some cells comprised eggs that had probably been laid in place of lost larvae, or there were eggs and larvae at the same time. Some cells were empty. In some cells, the royal jelly was altered and had solid instead of typical jelly-like consistency.

\subsubsection{Queen larva survival}

The results of the assessment of the survival of larvae transferred into cups made of paraffin- or stearin-adulterated wax were consistent with the findings concerning the survival of the worker brood. The survival rate in the queen larvae was significantly dependent on wax adulteration $\left(\mathrm{chi}^{2}=16.13, \mathrm{df}=2, p=0.000\right)$. There was no significant relationship between the survival of larvae in the pure wax cups and survival in the paraffin-adulterated wax cups $\left(\mathrm{chi}^{2}=1.91, \mathrm{df}=1\right.$, $p=0.167$ ). In turn, there was a relationship between larval survival in the pure wax cups and the survival rates in the stearin-adulterated wax cups 

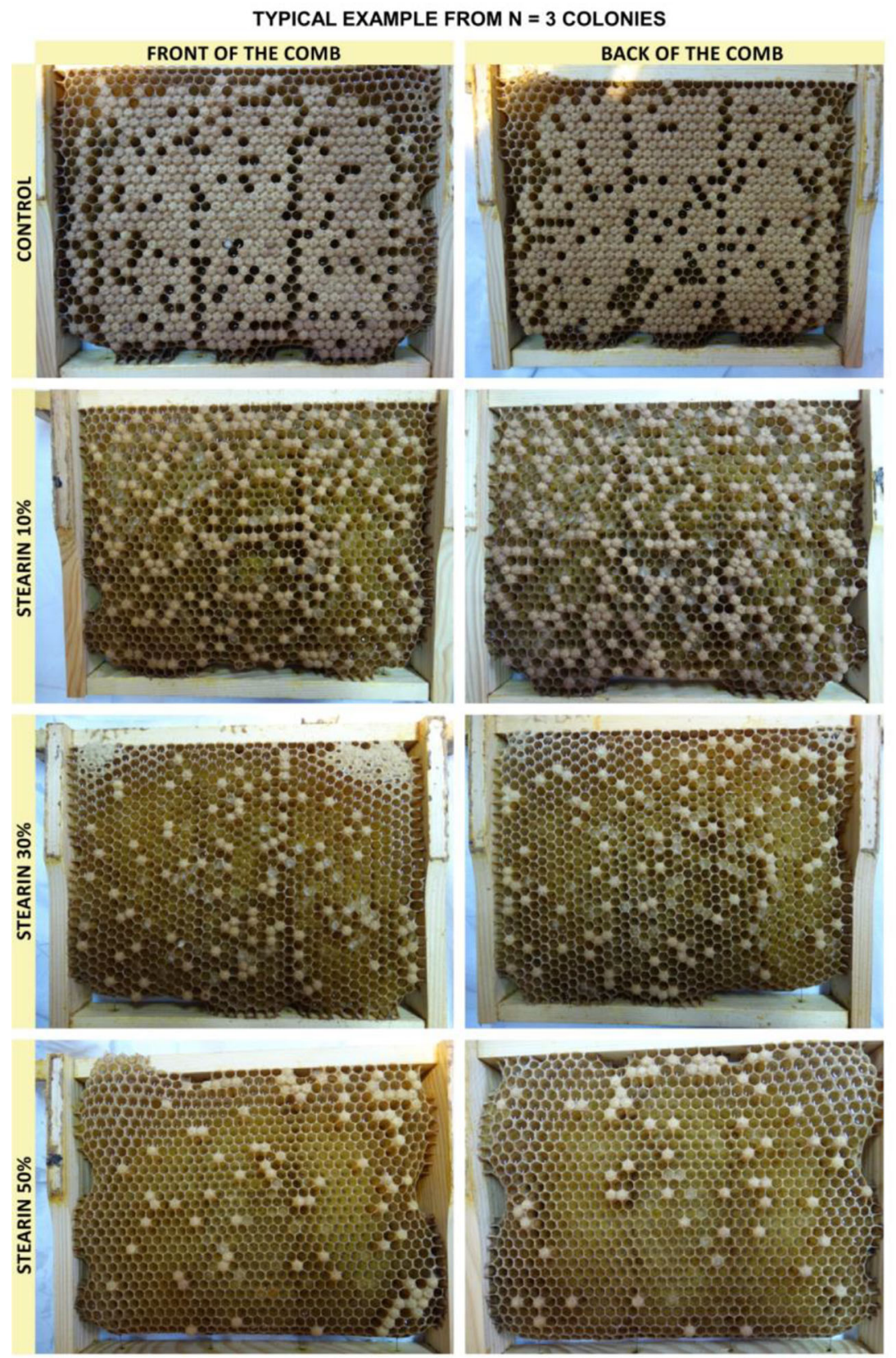

Figure 3. Experiment 2019, survival of the worker brood in combs built on wax foundation with the addition of stearin in relation to the control.

$\left(\mathrm{chi}^{2}=82.54, \mathrm{df}=1, p=0.000\right)$. The percentage of queen cells built on the pure wax and paraffinadulterated cups was similar, i.e., $88.89 \%$ and $81.25 \%$, respectively. In contrast, only $11.11 \%$ of queen cells were built on the stearinadulterated wax cups (Figures 8 and 9).

\section{DISCUSSION}

The study results demonstrated that a small addition of $10 \%$ stearin to the wax foundation significantly reduced (to $33 \%$ ) brood survival in the STCombs. A similar result was presented in 


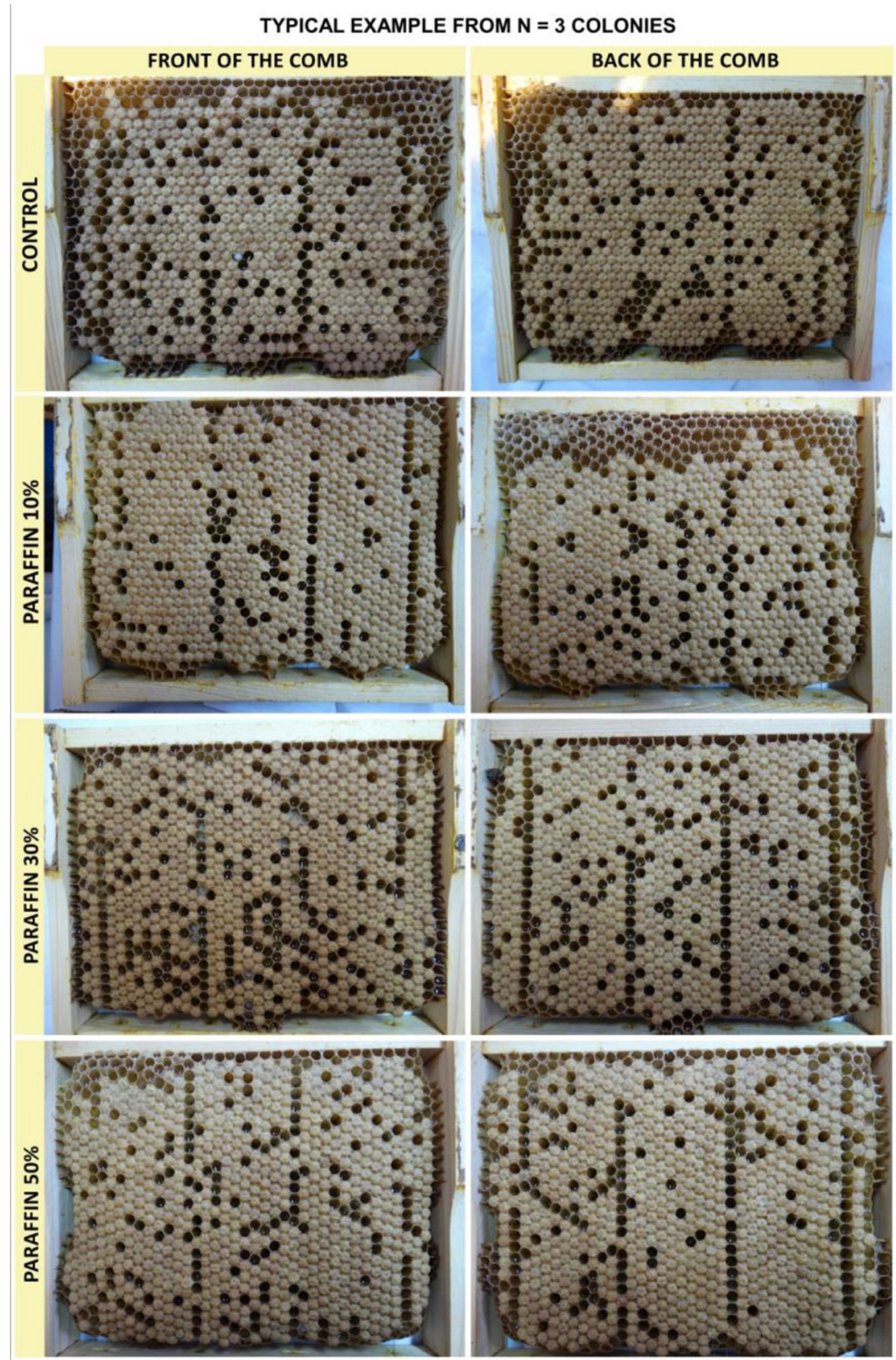

Figure 4. Experiment 2019, survival of the worker brood in combs built on wax foundation with the addition of paraffin in relation to the control.

one of the available reports (Reybroeck 2018), where a $35 \%$ decline in brood survival was already noted at $2.8 \%$ of stearic acid in the wax foundation. This allows an assumption that the negative effect of stearin is reflected in scattered brood even at a low content of the compound in the wax foundation. As shown by the EU Food Fraud Network (2018), 15-35\% stearic acid content in the wax foundation reduces brood survival up 49 to $71 \%$. Similar values were obtained by Reybroeck (2017), who reported that the brood survival decreased with the increase in the content 


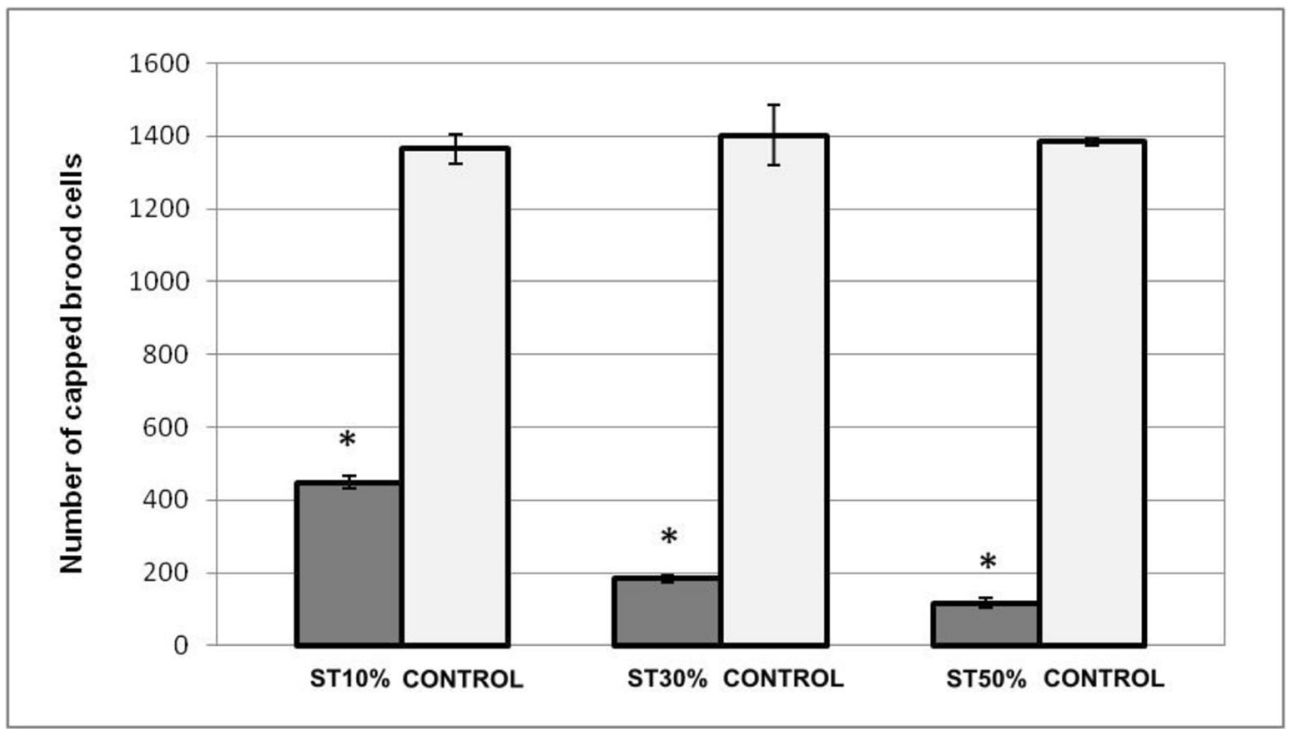

Figure 5. Number of capped brood cells in combs built on wax foundation with the addition of stearin in relation to the control. ST10\% — combs built on a 10\% stearin-adulterated wax foundation $(n=3)$; ST30\% — combs built on a $30 \%$ stearin-adulterated wax foundation $(n=3)$; ST50\% - combs built on a $50 \%$ stearin-adulterated wax foundation $(n=3)$; Control — combs built on a pure wax foundation $(n=3)$; *statistically significant differences relative to the control comb for each level of adulteration at $p \leq 0.001$; vertical bars indicate standard deviation.

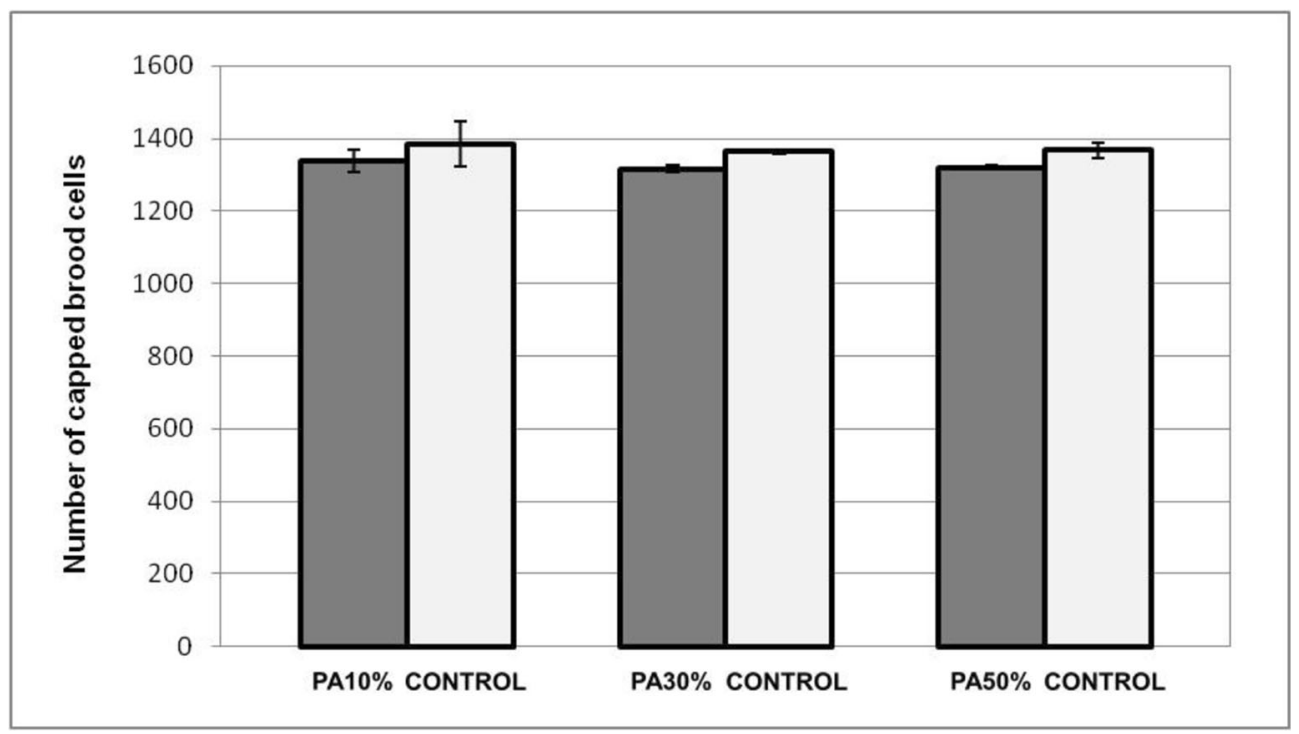

Figure 6. Number of capped brood cells in combs built on wax foundation with the addition of paraffin in relation to the control. PA10\% — combs built on a 10\% paraffin-adulterated wax foundation $(n=3)$; PA30\% — combs built on a 30\% paraffin-adulterated wax foundation $(n=3)$; PA50\% - combs built on a 50\% paraffin-adulterated wax foundation $(n=3)$; Control — combs built on a pure wax foundation $(n=3)$; vertical bars indicate standard deviation. 


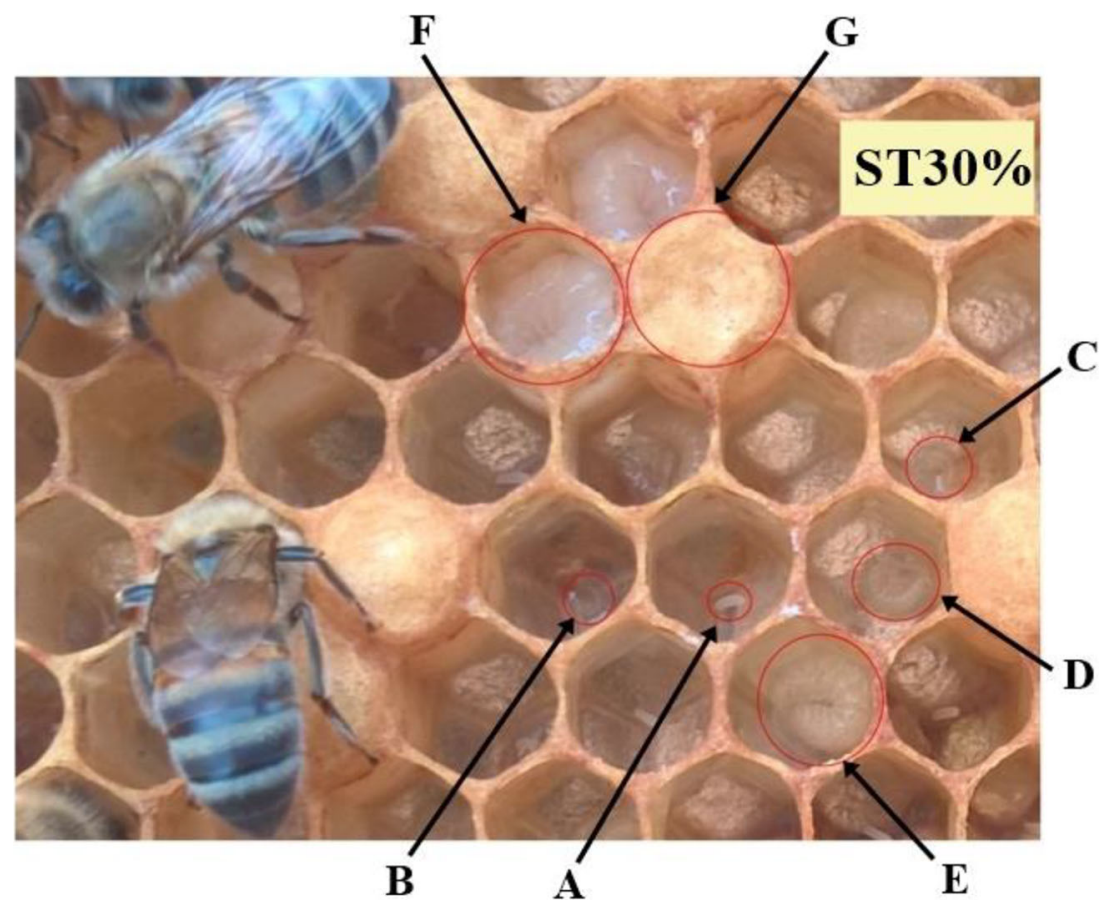

Figure 7. Characteristic image of scattered brood in comb built on a stearin-adulterated wax foundation (30\%). Various developmental stages in the neighboring cells: A—egg; B-2-3-day-old larva; C, D , E—older larvae; F - approx. 8-day-old larva; $\mathbf{G}$ —capped brood cell.

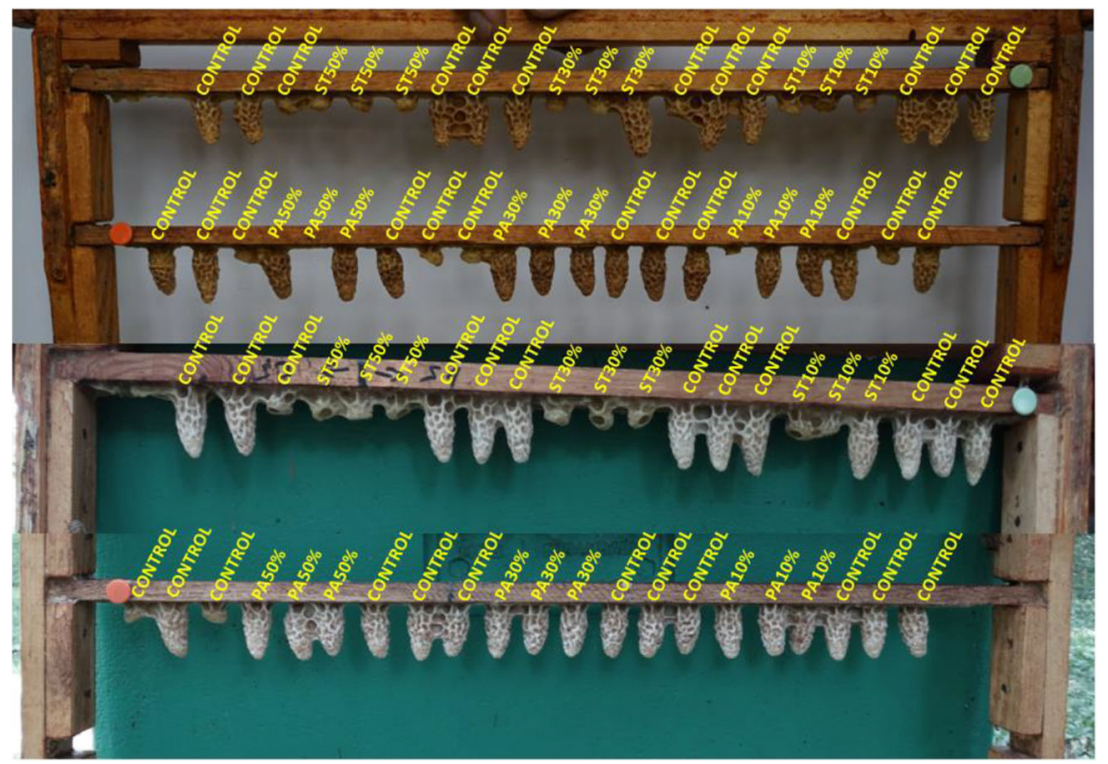

Figure 8. Queen cells built on cups formed from stearin- and paraffin-adulterated beeswax. ST, stearin-adulterated cups $(n=18)$; PA, paraffin-adulterated cups $(n=18)$; Control, pure beeswax cups $(n=48)$. 


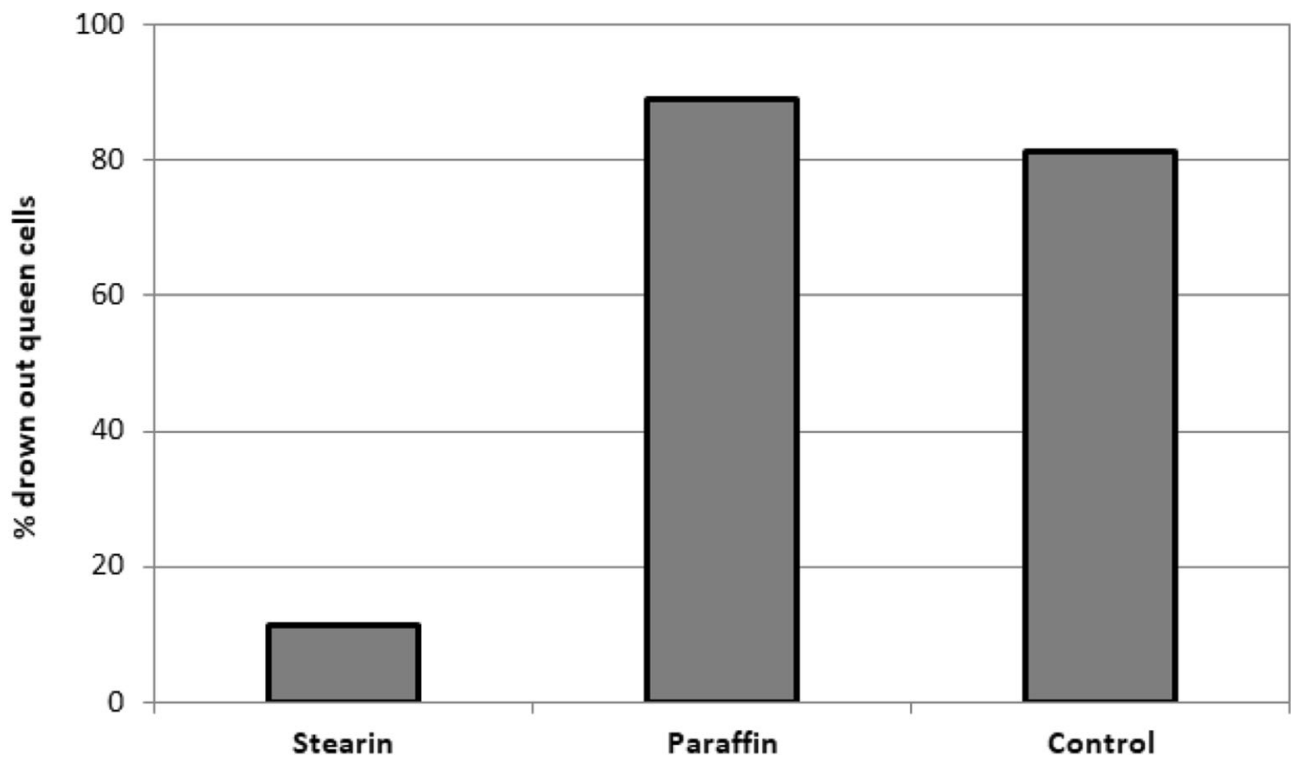

Figure 9. Percentage of queen cells built on pure beeswax cups (Control) and stearin- and paraffin-adulterated cups. Stearin, stearin-adulterated cups $(n=18)$; Paraffin, paraffin-adulterated cups $(n=18)$; Control, pure beeswax cups $(n=48)$.

of stearic acid in the wax foundation and was independent of the weather, nectar flow, queen bee, or the bee population. Similarly, Alkassab et al. (2020) reported a 55\% reduction of brood survival in combs constructed on a wax foundation containing 20\% stearin (no information on the content of stearic acid) and $442 \mu \mathrm{g} / \mathrm{kg}$ of fluvalinate compared to combs constructed on a wax foundation. The decrease in the survival rates was caused by was the addition of stearin, as no significant decrease in brood survival was noted in combs constructed on a wax foundation containing relatively high residues of varroacides: $2780 \mu \mathrm{g} / \mathrm{kg}$ fluvalinate, $169 \mu \mathrm{g} / \mathrm{kg}$ coumaphos, and $2900 \mu \mathrm{g} / \mathrm{kg}$ thymol. In the present study, the addition of merely $3.9 \%$ of stearic acid (ST10\%) significantly reduced brood survival to $33 \%$. In light of these results, the research results reported by Taranow (1959) have gained new implications, as they indicate a close relationship between the quality of wax used to build the wax foundation and the abundance of reared brood.

The EU Food Fraud Network (2018) does not specify whether scattered brood, which is characteristic in the case of stearin adulteration and has been observed in the present study and other investigations (Alkassab et al. 2020;
Reybroeck 2017; Reybroeck 2018), is related to the reduced brood survival. It can be assumed that the presence of scattered brood, which is a characteristic effect of stearin adulteration of the wax foundation, is rarely diagnosed correctly in apiaries. It is often wrongly attributed to the queen instead of adulterated wax foundations. At a low amount of stearin, the adulteration of the wax foundation may be overlooked by the beekeeper. This is especially common in professional apiaries where the time of interference in bee colonies is limited to a minimum or in colonies where single frames with an adulterated wax foundation or STCombs are introduced. In such a case, the colony collapse is delayed from the time of placement of the wax foundation; hence, the cause and effect relationship is difficult to be determined.

It should be noted that independent from bee health wax adulteration is not acceptable due to the quality of bee products and responsibility for consumer. The quality of the wax foundation should be the focus of special attention of beekeepers, as they resettle colonies only on frames with a wax foundation or on combs built on a wax foundation in the honey 
super. Particular attention to the quality of wax should also be paid by beekeepers rearing queens in beeswax cups. Our investigations show that stearin-adulterated wax is not suitable for rearing bee queens. Therefore, in case of any doubt about the quality of wax, the use of artificial cups seems to be the best solution.

It is puzzling why larvae developed in some STCombs cells but died in adjacent ones. This may be related to the uneven mixing of wax and stearin, although replacement of adulterated wax with pure wax by bees seems more probable.

We found that the larvae died in the STCombs at an early stage of development, and the process was induced by the change in the consistency of royal jelly. The royal jelly changes its consistency from gelatinous to a solid scab-like form. The consistency can be altered by the acidic/alkaline properties of stearin, i.e., a mixture of stearic and palmitic acids.

The paraffin wax adulteration did not significantly reduce the survival of the worker brood in the PACombs or the survival of the queen larvae in the paraffin-adulterated wax cups. Similar results were obtained by Semkiw and Skubida (2013).

Da Silva et al. (2002) suggested a possibility of using a paraffin-adulterated wax foundation for formation of combs used in honey supers; however, such combs were best accepted by bees in the honey super center. Studies showing no negative effect of paraffin adulteration on brood survival may encourage using this procedure. This may be linked with the wax deficit on the market and the absence of routine quality control of beeswax and wax foundations. However, due to the specific composition and properties of wax, the harmful effect of PACombs on the bee colony should not be considered only in terms of survival of brood. The impact of bee rearing in PACombs on the fitness of bees is unknown.

Although the PACombs did not exert a negative effect on brood survival, we noticed a serious drawback in the use of such a wax foundation in the apiary. In the preliminary experiment, combs built on a wax foundation containing $30 \%$ and $50 \%$ paraffin tended to slide vertically under the weight of accumulated food (frame $360 \mathrm{~mm} \times 260 \mathrm{~mm}$ ), which did not occur in the case of the stearin addition. In the study conducted by Semkiw and Skubida (2013), wax foundations with the addition of $10 \%, 20 \%$, and $40 \%$ of paraffin were built normally, but the wax foundation fragments occupied by the colonies had a smaller area, i.e., $1 / 2$ of the Dadant comb. The problem observed in the present study was not reported by Medici et al. (2012) and Castro et al. (2010) in their investigations of wax foundations with $20 \%$ and $40 \%$ paraffin addition. In the study conducted by Medici et al. (2012), the surface area of the adulterated wax foundation corresponded to $1 / 2$ of the Langstroth comb. In turn, Castro et al. (2010) used fragments of a wax foundation sized $70 \mathrm{~mm} \times 60 \mathrm{~mm}$. The relationship between the tendency of the comb to slide and the comb size can be confirmed by the fact that no destruction was observed in the case of the small combs (frame $210 \mathrm{~mm} \times 170 \mathrm{~mm}$ ) used in our study.

\section{CONCLUSIONS}

Stearin adulteration of beeswax makes it unsuitable to be used in apiculture and rearing bee queens, as even the lowest $10 \%$ level of stearin $(3.9 \%$ of stearic acid) significantly reduced brood survival. Therefore, a stearinadulterated wax foundation may be an unidentified cause of significant deterioration or loss of colonies.

The death of the larvae in the initial period was most likely caused by the change in the properties of royal jelly in contact with the stearin-adulterated beeswax.

Adulteration of wax with paraffin (up to $50 \%$ ) did not influence the survival of brood, but reduced the mechanical strength of the combs and protection against sliding under the weight of food. There is, however, no information about the effect of adulteration on the fitness of the bees reared in such combs. 


\section{AUTHOR CONTRIBUTIONS}

All authors have contributed to the concept and design of the research presented in this manuscript. The material was prepared, data was collected, and analyses were carried out by Magdalena Chęć, Krzysztof Olszewski, Piotr Dziechciarz, Patrycja Skowronek, Marek Pietrow, Grzegorz Borsuk, Mirosława Bednarczyk, Grzegorz Jasina, Józef Jasina, and Mariusz Gagoś. The first draft of the manuscript subjected to revisions made by all authors was written by Magdalena Chęć, Krzysztof Olszewski, and Mariusz Gagoś. Subsequent versions of the manuscript have also been revised by all authors of the study. All authors have read and approved the final version of the manuscript. Mariusz Gagoś was responsible for acquisition of funding.

$\mathrm{MC}$ - research, discussion, writing. $\mathrm{KO}$ - research, discussion, writing, research concept in apiary. PD, PS, GB, MP, MB - research. GJ and JJ from MG initial research. $\mathrm{MG}$ - concept, writing.

\section{Funding}

The research was part of the project "SUPPORT FOR PREIMPLEMENTATION OF RESEARCH RESULTS AND R\&D WORKS" within "Incubator Innovation 2.0" implemented by the consortium of Maria Curie-Skłodowska University in Lublin, John Paul II Catholic University of Lublin, Medical University of Lublin, and KUL Creative Sp. z o.o.

\section{Data availability}

All data generated or analyzed during this study are included in this published article. The datasets generated during and/ or analyzed during the current study are available from the corresponding author on reasonable request (mariusz.gagos@poczta.umcs.lublin.pl).

The datasets and materials used, analyzed, and presented in the manuscript are not publicly available. However, they may be made available by the relevant author upon a substantiated request from a third party.

\section{COMPLIANCE WITH ETHICAL STANDARDS}

Conflict of interest The authors declare that they are not affiliated with or involved in any organization or entity having any financial or non-financial interests in relation to the topic or material discussed in this manuscript.
Ethical approval The analyses are an observational study. In line with the ethical standards formulated by the Local Ethics Committee for Animal Experimentation at the University of Life Sciences in Lublin and the Declaration of Helsinki 1964 with subsequent amendments or with comparable ethical standards, no consent to conduct research on Apis mellifera insects is required.

No approval of the Research Ethics Committee was required to achieve the goals of this study, as the experimental work involved unregulated invertebrate species (Apis mellifera).

\section{OPEN ACCESS}

This article is licensed under a Creative Commons Attribution 4.0 International License, which permits use, sharing, adaptation, distribution and reproduction in any medium or format, as long as you give appropriate credit to the original author(s) and the source, provide a link to the Creative Commons licence, and indicate if changes were made. The images or other third party material in this article are included in the article's Creative Commons licence, unless indicated otherwise in a credit line to the material. If material is not included in the article's Creative Commons licence and your intended use is not permitted by statutory regulation or exceeds the permitted use, you will need to obtain permission directly from the copyright holder. To view a copy of this licence, visit http://creativecommons. org/licenses/by/4.0/.

Effet de la falsification de la cire d'abeille par la stéarine et la paraffine sur la survie du couvain

Apis mellifera / falsification de la cire / paroi médiane /
stéarine / paraffine

Einfluss von Stearin- und Paraffin-Verfälschungen des Bienenwachses auf das Überleben der Bienenbrut

Apis mellifera / Wachsverfälschungen / Mittelwand / Stearin / Paraffin

\section{REFERENCES}

Alkassab A, Thorbahn D, Frommberger M, Bischoff G, Pistorius J (2020) Effect of contamination and adulteration of wax foundations on the brood development of 
honeybees. Apidologie 51:642-651. https://doi. org/10.1007/s13592-020-00749-2

Aupinel P (2018) ExpËrimentation visant $\$$ dÈmontrer le possible effet dElĖtËre de cires adultĖrÈes sur le dĖveloppement du couvain díabeilles. Rapport díEssais, RÈf.: E-LAB-12-07: October 18, 2018. INRA-Station du Magneraud, SurgÈres, France: 15. (Unpublished Report)

Bogdanov S (2016) Beeswax: History, Uses, Trade. Bee Product Science Chapter I:1-18

Calatayud-Vernich P, Calatayud F, Simo E, Pico Y (2017) Occurrence of pesticide residues in Spanish beeswax Sci Total Environ 605:745-754. https://doi. org/10.1016/j.scitotenv.2017.06.174

Castro AV, Medici SK, G SE, J EM (2010) Effects of Paraffin Incorporation in Beeswax Foundations on Comb-building and Brood Survivorship in Apis mellifera Colonies Zootecnia Tropical 28:353-361

Chen YP, Evans JD (2007) Historical presence of Israeli acute paralysis virus in the United States Am Bee J 147:1027-1028

Cuní J, Cuni P, Eisen B, Savizky R, John B (2012) Characterization of the binding medium used in Roman encaustic paintings on wall and wood Anal Methods 4:659-669. https://doi.org/10.1039/C2AY05635F

da Silva CR, da Rocha Ribeiro L, Toledo VAA, Toledo JOA (2002) Uso da parafina incorporada à cera alveolada em colônias de abelhas Apis mellifera L. africanizadas para produçào de mel. Acta Scientiarum 24:875-879. https://doi.org/10.4025 /actascianimsci.v24i0.2336

Daniele G, Giroud B, Jabot C, Vulliet E (2018) Exposure assessment of honeybees through study of hive matrices: analysis of selected pesticide residues in honeybees, beebread, and beeswax from French beehives by LC-MS/MS Environ Sci Pollut R 25:6145-6153. https://doi.org/10.1007/s11356-017-9227-7

Eshete Y, Eshetie T (2018) A review on crude beeswax mismanagement and lose: opportunities for collection, processing and marketing in Ethiopia Journal of Nutritional Health \& Food Engineering 8:384-389

EU Food Fraud Network (2018) Coordinated Case. European Commision. Adulteration of beeswax intended for honey production with stearin and paraffin [online] https:/ec. europa.eu/food/sites/food/files/safety/docs/food-fraud succ-coop_beeswax.pdf (accessed march 25, 2018)

European Food Safety Authority (2007) Beeswax (E 901) as a glazing agent and as carrier for flavours - Scientific Opinion of the Panel on Food additives, Flavourings, Processing aids and Materials in Contact with Food (AFC) EFSA Journal 5:615. https://doi.org/10.2903/j. efsa.2007.615

European Food Safety Authority (2020) Risk assessment of beeswax adulterated with paraffin and/or stearin/stearic acid when used in apiculture and as food (honeycomb) EFSA supporting publication 2020:EN-1859 64pp. https://doi.org/10.2903/sp. efsa.2020.EN-1859
Johnson RM, Evans JD, Robinson GE, Berenbaum MR (2009) Changes in transcript abundance relating to colony collapse disorder in honey bees (Apis mellifera) P Natl Acad Sci USA 106:14790-14795. https://doi. org/10.1073/pnas.0906970106

Medici SK, Castro A, Sarlo EG, Marioli JM, Eguaras MJ, (2012) The concentration effect of selected acaricides present in beeswax foundation on the survival of Apis mellifera colonies J Apicult Res 51:164-168

Medici SK, Maggi MD, Sarlo EG, Ruffinengo S, Marioli JM, Eguaras MJ (2015) The presence of synthetic acaricides in beeswax and its influence on the development of resistance in Varroa destructor J Apicult Res 54:267274. https://doi.org/10.1080/00218839.2016.1145407

Reybroeck W (2017) Field trial: effect of the addition of a mixture of stearic and palmitic acid (called stearin) to beeswax on the development of the worker bee brood. Final report: ILVO, Melle, 1-14. [online] https://www.health.belgium.be/de/node/31713 (accessed September 6, 2020)

Reybroeck W (2018) Field trial: effect of the addition of stearic and palmitic acid to beeswax on the development of the worker bee brood, Final report: ILVO, Melle, 1-22. [online] https://www.health.belgium. $\mathrm{be} / \mathrm{sites} / \mathrm{default} / \mathrm{files} / \mathrm{uploads} /$ fields/fpshealth theme file/verslag_veldproef_ilvo_2018_eng.pdf (accessed September $\overline{6}, 2020$ )

Sauer S, Herrmann E, Kaiser W (2004) Sleep deprivation in honey bees J Sleep Res 13:145-152. https://doi. org/10.1111/j.1365-2869.2004.00393.x

Semkiw P, Skubida P (2013) Comb Construction and Brood Development on Beeswax Foundation Adulterated with Paraffin J Apic Sci 57:75-83. https://doi. org/10.2478/jas-2013-0009

Svečnjak L, Baranović G, Vinceković M, Prđun S, Bubalo D, Tlak Gajger I (2015) An approach for routine analytical detection of beeswax adulteration using FTIRATR spectroscopy J Apic Sci 59:37-49. https://doi. org/10.1515/JAS-2015-0018

Tarranow GF (1959) The production of wax in the honeybee colony Bee World 40:113-121

Tulloch AP (1973) Factors affecting analytical values of beeswax and detection of adulteration Journal of the American Oil Chemists Society 50:269-272

vanEngelsdorp D, Traynor KS, Andree M, Lichtenberg EM, Chen YP, Saegerman C, Cox-Foster DL (2017) Colony Collapse Disorder (CCD) and bee age impact honey bee pathophysiology Plos One 12. https://doi.org/10.1371 /journal.pone.0179535

Wilmart O et al. (2016) Residues in Beeswax: A Health Risk for the Consumer of Honey and Beeswax? J Agric Food Chem 64:8425-8434. https://doi. org/10.1021/acs.jafc.6b02813

Publisher's note Springer Nature remains neutral with regard to jurisdictional claims in published maps and institutional affiliations. 